----- Raf. J. Sci., Vol. 24, No.2 pp. 82-91, 2013------

\title{
The Effect of Bore Diameters in Two Electrodes Electrostatic Immersion Lens Design
}

\author{
Muna A. Al-Khashab Abdullah E. Al-Abdullah \\ Department of Physics \\ College of Science \\ University of Mosul
}

(Received 13/5/2012 ; Accepted 8/10/2012)

\begin{abstract}
The paper handles a new method that is utilized in determining the best bore diameter of two electrodes of the electrostatic lens design. However, the bore diameter is considered the most important geometrical parameter in any electron optical device. Accordingly, the immersion electrostatic lens have been designed and its electron optical properties were calculated for different bore diameters of the two electrodes to determine their optimum value. Also the study is concerned with the equal values of the bore diameter for the two electrodes, and the ratios of their first to the second bore diameters found including the calculated value of the optimum bore diameter. It was found that the best electron optical properties were obtained when the ratio of the bore diameters for the electrostatic lens is approximately equal (0.66).
\end{abstract}

Keywords: electrostatic immersion lens design, ratio of the two electrodes bore diameter, electron optical properties.

\section{تألثير ألغارفتحة الفلبين عل تصميم العسلت الكهروستالتيكية شنائية الغلب المغورة}

\section{الملغص}

يتناول هذا البحثطريقة جدية لإيجاد افضل قيمة التطر فتحة التطبين في تصميم العهسة الكهروستاتيكية.

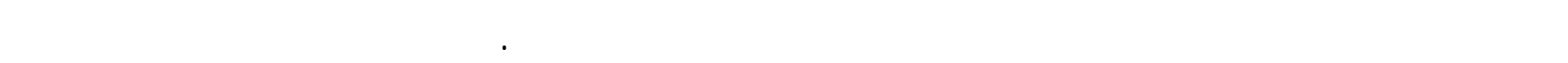
الكتروستاتيكية مغمورة، وم لحتسب خواصها البصرية الالكترونية لقيم مختلفة من اقطار فتحة التطبين لإيجاد

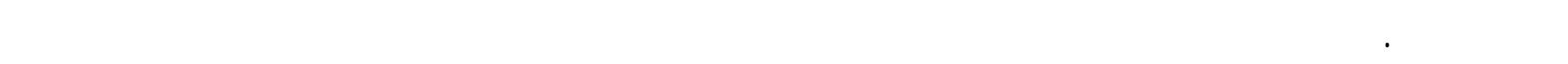

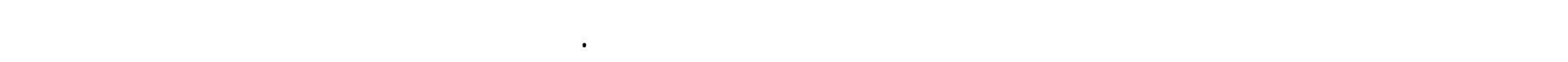
قم الحصول عليها عند نسبة قطر فتحة قطبي العهسة الكهروستاتيكية تساوي نقريبا (0.66). الكاملت الدالة: تصميم العهلت الكهروستاتيكية المغمورة، غنبة قطر فتحلت قطبيها، الخواص البصرية الالكترونية. 


\section{INTRODUCTION}

Electrostatic lenses are used for the extraction, focusing, deceleration and acceleration of electron and ion beams. It is of great importance in the design of low energy electrostatic accelerators like Cockcroft Walton and Van de Graff accelerators (Hinterberger, 2005). Recently add-on immersion electrostatic-magnetic lens attachments have been designed to improve the resolution of conventional scanning electron microscopes (SEMs) which acquire images with a resolution of better than $4 \mathrm{~nm}$ at a landing energy of $600 \mathrm{eV}$ (Khursheed and Karuppiah, 2002).

The theory of electrostatic lenses were developed since many years ago i.e., between 1930-1955. The solution of the paraxial ray equation and the introduction of the matrix formalism were illustrated by (Septier, 1980) and (Liebl, 2008). The solution of the paraxial ray equation at relativistic energies were given by (Zworykin et al., 1945) and (Lawson, 1988). Ion optics with rotational symmetric electrostatic lenses were presented by (Hinterberger, 2005). Accurate and extensive data calculation on the objective focal properties and the third-order aberration of electrostatic lenses were found by (Grivet, 1965) and (Hawkes and Kasper, 1996). Progress in the calculation of electron optical properties in recent years have been reviewed by (Hawkes, 2004) and (Sise et al., 2005).

Intensive studies have been rigorously carried out to optimize the geometrical structure and the dimensions of the electrostatic lens. New models of the asymmetrical electrostatic immersion lenses have been introduced by (Al-Khashab and Al-Shamma, 2009). The electrostatic einzel lens fabricated using micro-fabrication technology has been described by (Syms et al., 2003). The design and fabrication of cylindrical multi-element electrostatic lenses at the nanoscale down to $140 \mathrm{~nm}$ in aperture diameter and $4.2 \mu \mathrm{m}$ in column length were presented by (Sinno et al., 2010).

In the present work, we introduce a new design of the electrostatic immersion lens combined from the planar-apertured electrodes and the tubular electrodes. The effect of the electrodes bore diameters on the electron optical performance is studied systematically to obtain the best ratio of the electrode diameters. This design is suitable for the fabrication of the immersion electrostatic lens to be used as focusing system for the electron gun design was presented by (Al-Khashab and Al-Abdullah, 2012).

\section{Design Consideration}

The cross section of the prototype electrostatic immersion lens with its dimensions and geometrical parameters are shown in Fig. (1). The first electrode of truncated conical bore shaped facing the incident electron beam of applied voltage is denoted by $\left(\mathrm{V}_{1}\right)$, while the second electrode facing the image side and has the cylindrical bore shaped of applied voltage denoted by $\left(\mathrm{V}_{2}\right)$, and the bore diameter for the two electrodes are denoted by $\left(\mathrm{D}_{1}\right)$ and $\left(\mathrm{D}_{2}\right)$, respectively. The bore angle of the first electrode has been denoted by $(\theta)$ equals $\left(8^{\circ}\right)$. The space between the two electrodes is denoted by $(\mathrm{L})$ equals $(10 \mathrm{~mm})$. 


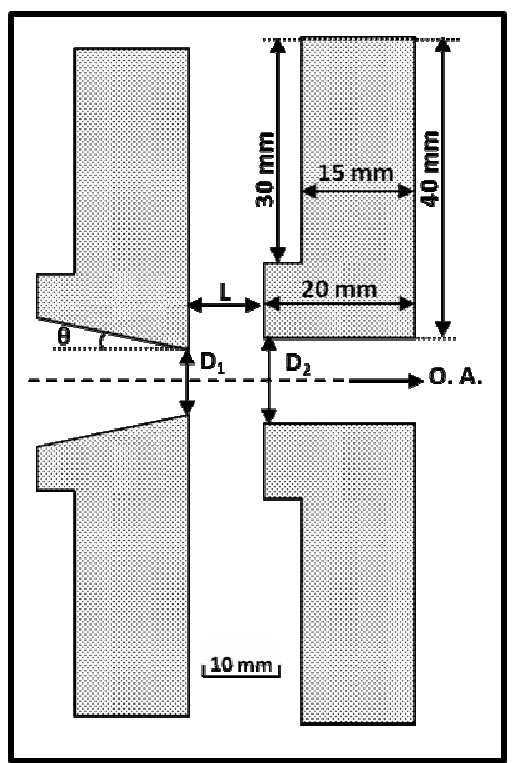

Fig. 1: Cross section of the electrostatic immersion lens with the geometrical dimensions and geometrical parameters

\section{PROCEDURE AND RESULTS}

In order to determine the best bore diameter for the two electrodes immersion lens, the electron optical properties have been calculated and compared systematically by using constant electrodes voltage at the finite magnification condition of operation (Munro, 1975). The calculations are accomplished by using a modified version of some Munro's programs (Munro, 1975). The modification is fulfilled in this research and includes the enhancement of the fine and coarse mesh number in the axial and radial directions which provide more accurate finite element calculations, and also necessary for handling the complicated shapes design. Moreover, the programs are modified to calculate and illustrate the electron trajectories inside the lens structure.

The spherical aberration coefficient $\mathrm{C}_{\mathrm{s}}$ and the chromatic aberration coefficient $\mathrm{C}_{\mathrm{c}}$ are considered the best criterion for the comparison between the optical instruments (Hawkes and Kasper, 1996). These coefficients can be calculated numerically from the following nonrelativistic formulas using Simpson's rule (Szilagyi and Szep, 1988):

$$
\begin{aligned}
& C_{s i}=\frac{1}{16 v_{i}^{4 / 4} r_{i}^{f 4}} \int_{Z_{a}}^{Z_{i}}\left\{\left[\frac{5}{4}\left(\frac{V^{\prime r}}{V}\right)^{2}+\frac{5}{24}\left(\frac{V^{f}}{V}\right)^{4}\right] r^{3}+\frac{14}{3}\left(\frac{V^{f}}{V}\right)^{4} r^{\prime 3} r^{3}-\frac{3}{2}\left(\frac{V^{f}}{V}\right)^{2} r^{\prime 2} r^{2}\right\} V^{1 / 2} d z \\
& C_{c i}=\frac{v_{i}^{i s}}{r_{i}^{\prime 4}} \int_{Z_{o}}^{Z_{i}}\left(\frac{V^{\prime}}{2 V} r^{\prime} r+\frac{V^{\prime \prime}}{4 V} r^{2}\right) V^{-1 / 2} d z
\end{aligned}
$$

where $\left(C_{s i}\right)$ and $\left(C_{c i}\right)$ are the spherical and chromatic aberration coefficients at the image plane position, respectively. $\left(Z_{o}\right)$ and $\left(Z_{i}\right)$ are the object and image plane position, respectively. $\left(V_{i}\right)$ is the potential at the image plane, $\left(V^{\prime}\right)$ and $\left(V^{\prime \prime}\right)$ are the first and second derivatives of the axial 
potential. $(r)$ is the electron trajectories, $\left(r_{i}{ }^{\prime}\right)$ is the slope of the electron trajectories at each point which can be found using the following paraxial ray equation:

$$
r^{\prime \prime}(Z)+\frac{V^{\prime}}{2 V} r^{\prime}(Z)+\frac{V^{\prime \prime}}{4 V} r(Z)=0
$$

where $\left(r^{\prime}\right)$ and $\left(r^{\prime \prime}\right)$ are the first and second derivatives of the electron trajectory. The above equation can be solved numerically using the fourth order Range-Kutta method (Hawkes, 1972).

\section{Determination of the suitable electrodes voltage}

The values of $\left(\mathrm{C}_{\mathrm{s}}\right)$ and $\left(\mathrm{C}_{\mathrm{c}}\right)$ were calculated at a wide range of $\left(\mathrm{V}_{1}\right)$ and at a constant value of $\left(\mathrm{V}_{2}=3 \mathrm{kV}\right)$ as illustrated in Fig. (2). This figure shows that the preferable compromise optical properties are acquired at $\left(\mathrm{V}_{1}=100 \mathrm{~V}\right)$. Accordingly, in this paper we shall use $\left(\mathrm{V}_{1}=100 \mathrm{~V}\right)$ as a constant value in the following computations.

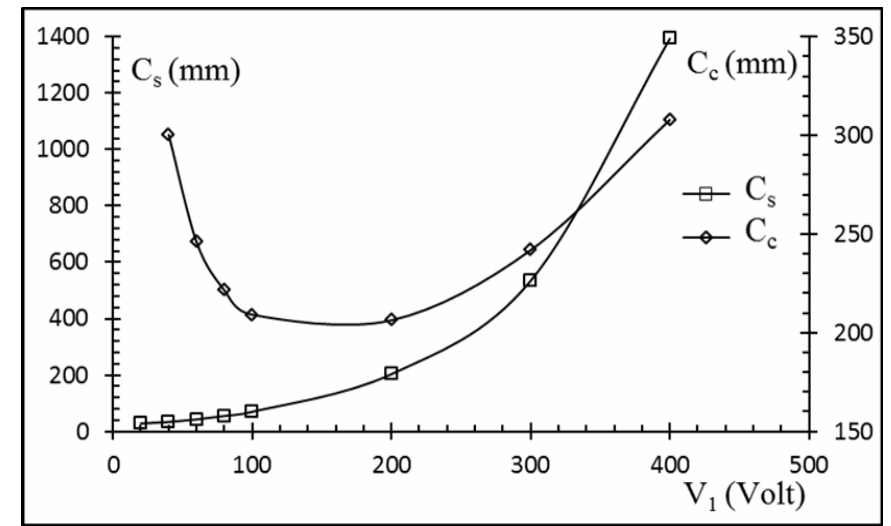

Fig. 2: Variation of the spherical aberration coefficient $C_{s}$ and chromatic aberration coefficient $C_{c}$ as a function of the first electrode voltage $\left(V_{1}\right)$, calculated at a constant applied voltage of the second electrode $\left(V_{2}=3 \mathrm{kV}\right)$ at the finite magnification condition.

Moreover, the values of $\left(\mathrm{C}_{\mathrm{s}}\right)$ and $\left(\mathrm{C}_{\mathrm{c}}\right)$ have been calculated at a wide range of $\left(\mathrm{V}_{2}\right)$ and at a constant value of $\left(\mathrm{V}_{1}=100 \mathrm{~V}\right)$ as illustrated in Fig. (3). From this figure, the preferable voltage on the second electrode has been chosen at $\left(\mathrm{V}_{2}=3 \mathrm{kV}\right)$, this value produces a best compromise corresponding values of $\left(\mathrm{C}_{\mathrm{s}}\right)$ and $\left(\mathrm{C}_{\mathrm{c}}\right)$. Accordingly, we shall consider $\left(\mathrm{V}_{2}=3 \mathrm{kV}\right)$ as a constant value in the following computations. 


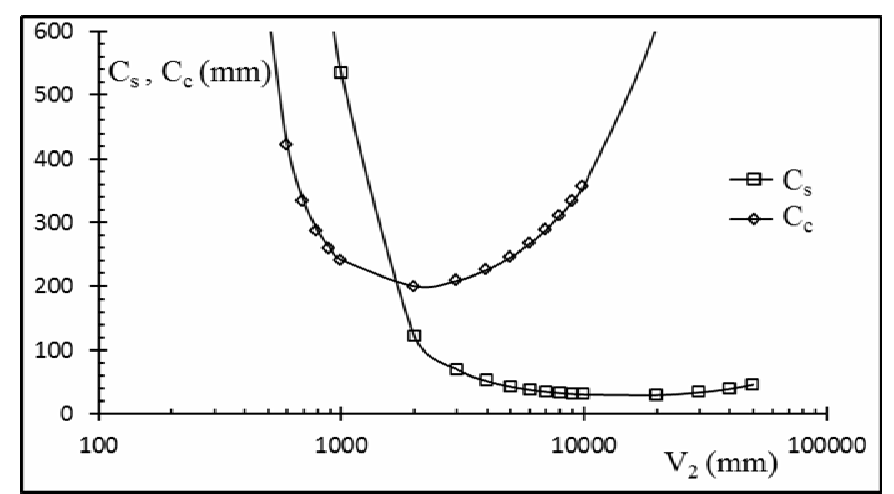

Fig. 3: Variation of the spherical aberration coefficient $C_{s}$ and chromatic aberration coefficient $C_{c}$ as a function of the second electrode voltage $\left(V_{2}\right)$, calculated at constant applied voltage of the first electrode $\left(V_{1}=100 \mathrm{~V}\right)$ at the finite magnification condition.

\section{Determination of the object plane position}

Since the mode of operation for the electrostatic lens is the "finite magnification condition" so it is necessary to determine the object plane position $\left(Z_{o}\right)$, see (Munro, 1975). Fig. (4) shows the variation of the spherical and chromatic aberration coefficients with the object plane position $\left(Z_{o}\right)$. This figure shows that the stable values of $\left(C_{s}\right)$ and $\left(C_{c}\right)$ are acquired at the range of $\left(Z_{\mathrm{o}}\right)$ greater than $(100 \mathrm{~mm})$. Accordingly, we shall use $\left(Z_{\mathrm{o}}=114 \mathrm{~mm}\right)$ as a constant value in the calculation of the optical properties.

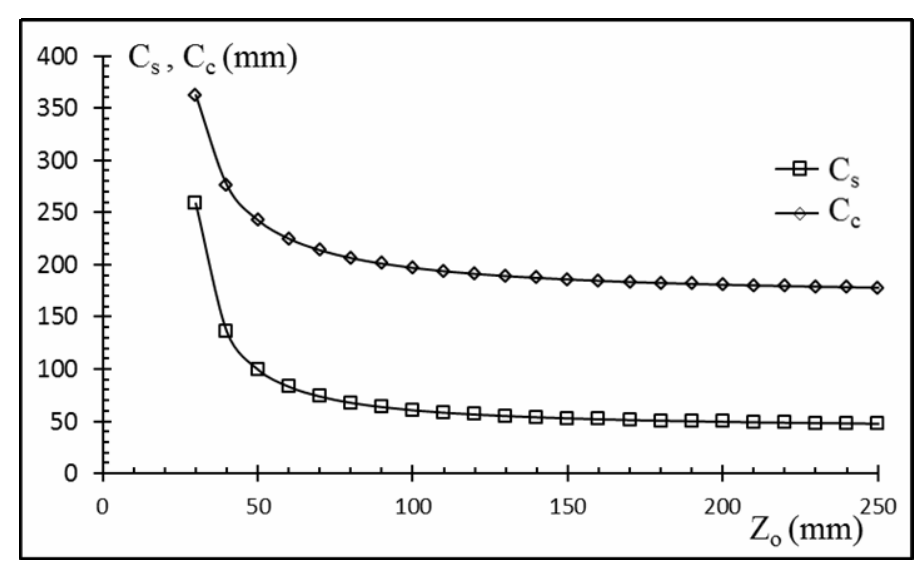

Fig. 4: Variation of the spherical and chromatic aberration coefficients as a function of the image plane position $\left(Z_{0}\right)$, calculated at a constant applied voltage of the first and second electrodes $\left(V_{1}=100 \mathrm{~V}\right.$ and $\left.V_{2}=3 \mathrm{kV}\right)$, at the finite magnification condition. 


\section{Optimizing of the two electrodes bore diameters}

To determine the best value for the two electrodes of the electrostatic immersion lens, the procedure is divided into two parts.

\section{Part I}

In the first part, the values of $\left(D_{1}\right)$ is taken equal to $\left(D_{2}\right)$ and both are chosen equal to $(2$, 4, 6, 8, 10 and 12) $\mathrm{mm}$. Accordingly, the axial potential distribution has been calculated for each value of the bore diameter and is compared with each other as given in Fig. (5). This figure shows that the axial potential increases steadily and regularly as the values of bore diameter increases.

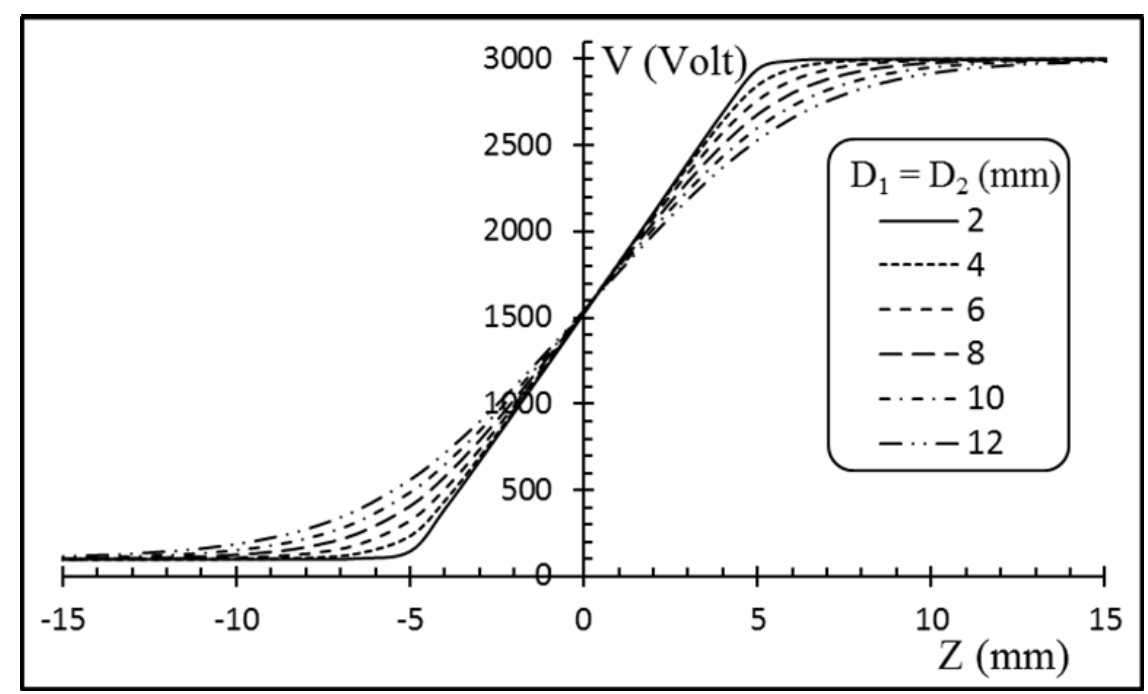

Fig. 5: Variation of the axial potential distribution of different values of the electrodes bore diameter $\left(D_{1}=D_{2}\right)$, calculated at a constant applied voltage of the first and second electrodes $\left(V_{1}=100 \mathrm{~V}\right.$ and $\left.V_{2}=3 \mathrm{kV}\right)$.

In addition, the equipotential lines trajectories inside the lenses structures are calculated and compared with each other as given in Fig. (6). This figure shows that the field stray increases inside the bore as the bore diameter increases. However, the more uniform equipotential line gives the best optical properties. Moreover, the electron beam trajectories in the radial direction $(\mathrm{R})$ are calculated for each electrode bore diameter value and compared with each other as illustrated in Fig. (7). This figure shows that the cross-over point has been shifted toward the image side as the bore diameter increases. 


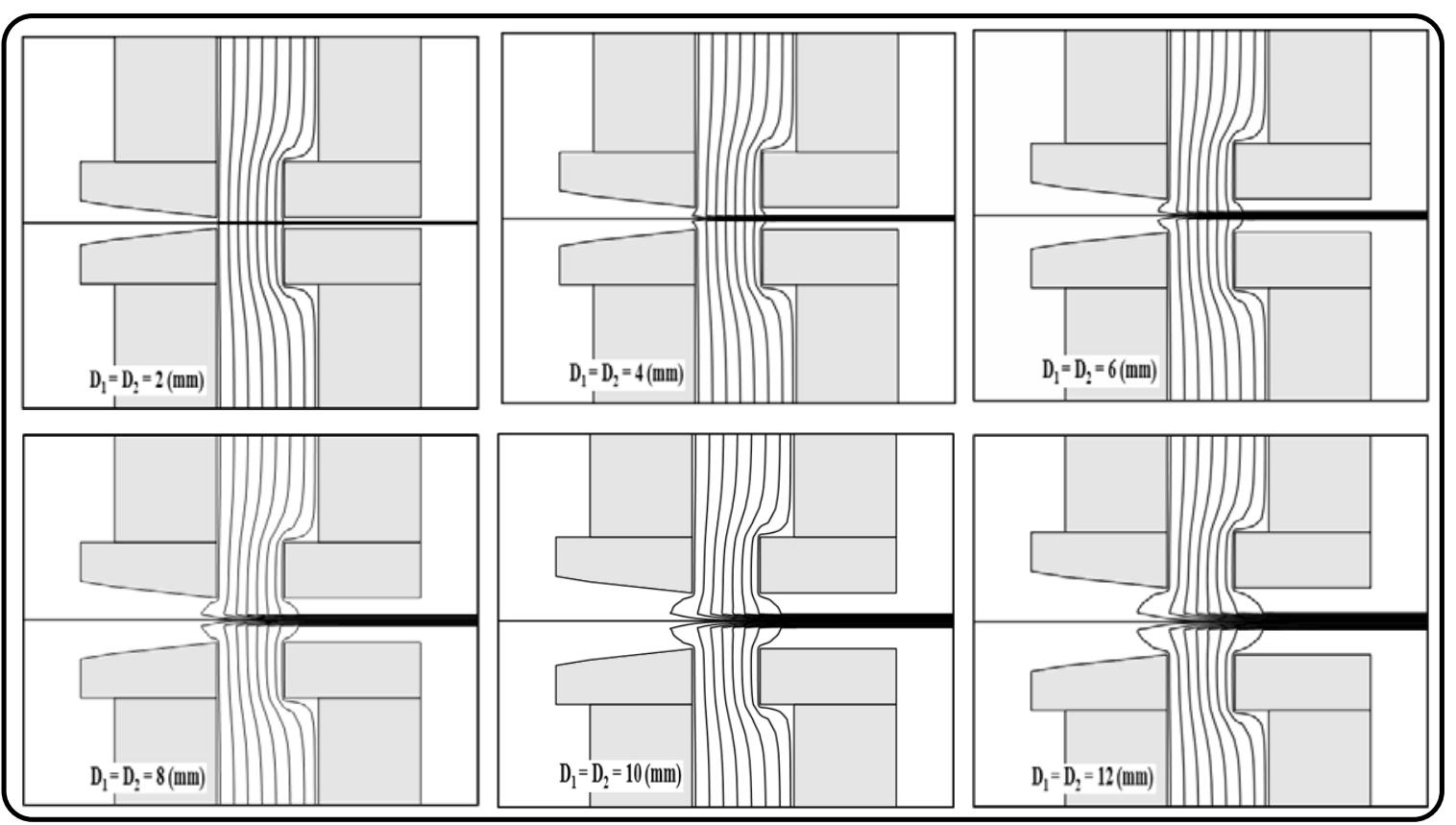

Fig. 6: Variation of the equipotential lines for different values of the electrodes bore diameter $\left(D_{1}=D_{2}\right)$, calculated at a constant applied voltage of the first and second electrodes $\left(V_{1}=100 \mathrm{~V}\right.$ and $\left.V_{2}=3 \mathrm{kV}\right)$.

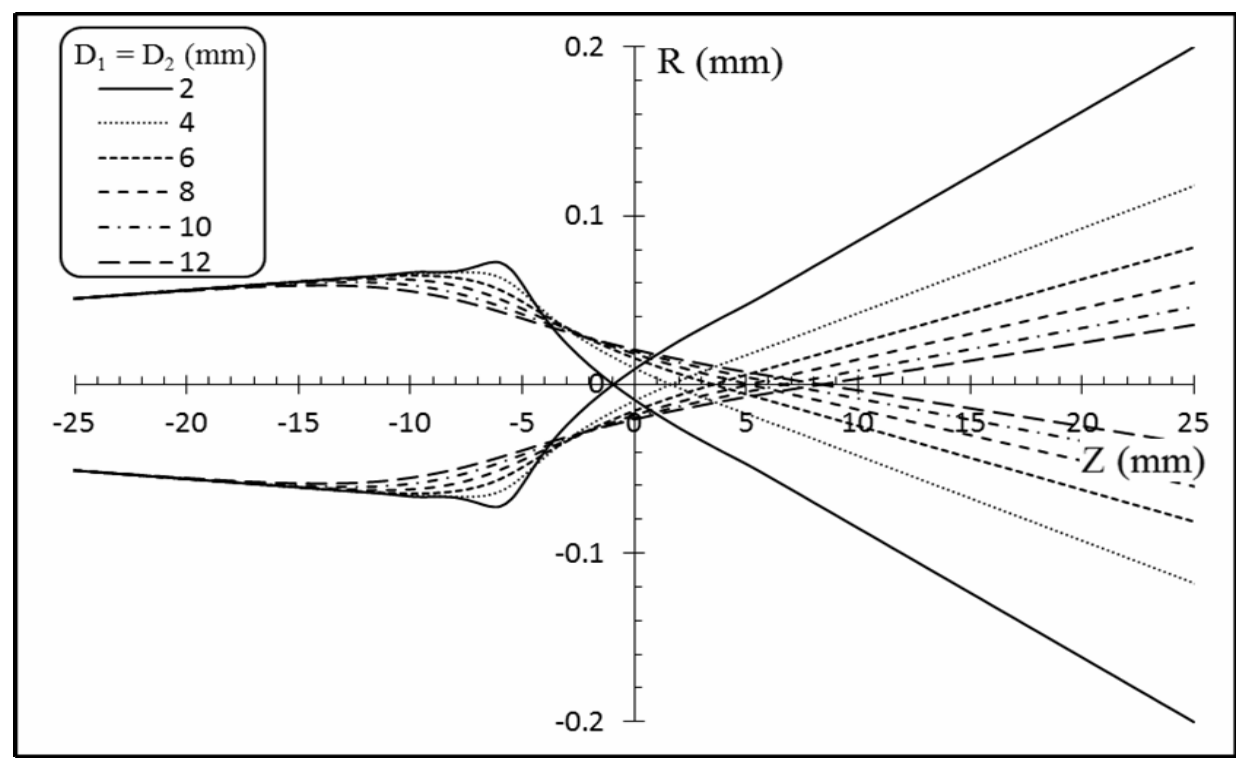

Fig. 7: The electron beam trajectories of different values of the electrodes bore diameter $\left(D_{1}=D_{2}\right)$, calculated at a constant applied voltage of the first and second electrodes $\left(V_{1}=100 \mathrm{~V}\right.$ and $\left.V_{2}=3 \mathrm{kV}\right)$, at the finite 
Moreover, the spherical and chromatic aberration coefficients have been calculated for the range of electrodes bore diameter that are mentioned previously $\left(D_{1}=D_{2}\right)$ at the same electrodes voltages $\left(V_{1}=100 \mathrm{~V}\right.$ and $\left.V_{2}=3 \mathrm{kV}\right)$ of object plane position $\left(Z_{\mathrm{o}}\right)$ that equals $(114 \mathrm{~mm})$ using the "finite magnification condition" as shown in Fig. (8). It is noticed that the best compromise values of $\left(C_{s}\right)$ and $\left(C_{c}\right)$ are achieved at $\left(D_{1}=D_{2}=6 \mathrm{~mm}\right)$.

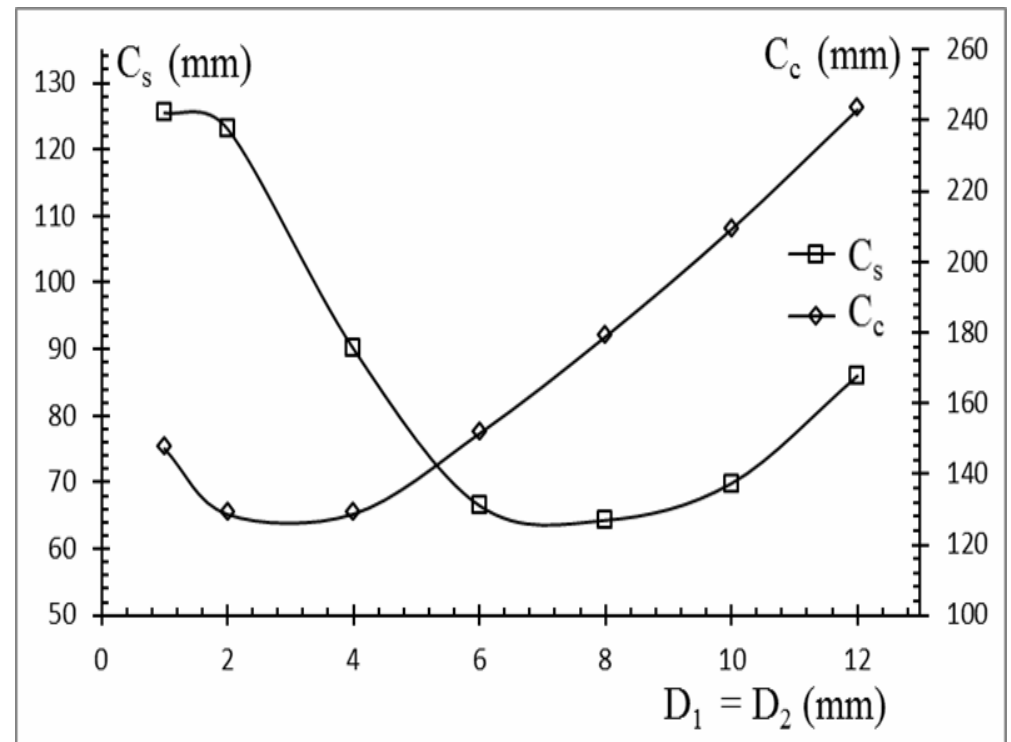

Fig. 8: Variation of the spherical aberration coefficient $C_{s}$ and chromatic aberration coefficient $C_{c}$ with the equal values of the electrodes diameter $D_{1}=D_{2}$, calculated at $\left(V_{1}=100 \mathrm{~V}\right.$ and $\left.V_{2}=3 \mathrm{kV}\right)$, using the finite magnification condition.

\section{Part II}

This part is concerned with the determination of the relative value of the two electrodes diameters $\left(\mathrm{D}_{1} / \mathrm{D} 2\right)$; see (Heddle, 2000). The selected values of this ratio are equal to $(0.33$, $0.66,0.75,1,1.5$ and 3 ). According to the following method of this work, the determination of these values will be based on the result deduced from the previous part i.e. $\left(D_{1}=D_{2}=6 \mathrm{~mm}\right)$. Correspondingly, the above ratios will be deduced from the diameters values $(2 / 6,4 / 6,6 / 8,6 / 6$, $6 / 4$ and 6/2) respectively.

The spherical and the chromatic aberration coefficients of the lens have been calculated for the values of the electrodes bore diameters mentioned previously and compared in Fig. (9). The calculation has been carried out at the same electrodes voltages $\left(\mathrm{V}_{1}=100 \mathrm{~V}\right.$ and $\mathrm{V}_{2}=$ $3 \mathrm{kV})$ and object plane position $\left(\mathrm{Z}_{\mathrm{o}}=114 \mathrm{~mm}\right)$ using the "finite magnification condition". Fig. (9) shows that the best compromise values of $\left(C_{s}\right)$ and $\left(C_{c}\right)$ achieved at $\left(D_{1} / D_{2}=0.66\right)$. This ratio is corresponding to the bore diameter values $\left(\mathrm{D}_{1}=4 \mathrm{~mm}\right.$ and $\left.\mathrm{D}_{2}=6 \mathrm{~mm}\right)$. 


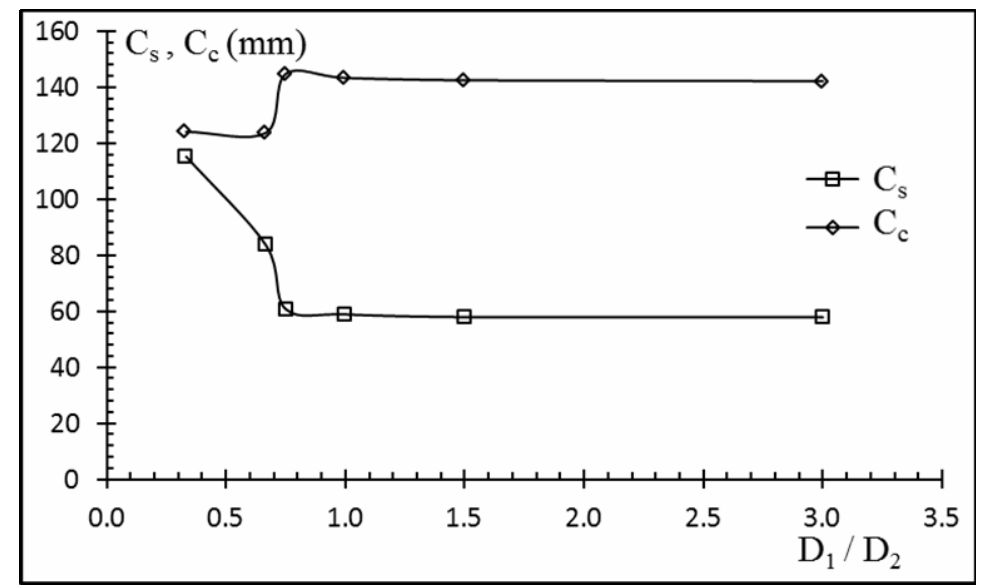

Fig. 9: Variation of the spherical and chromatic aberration coefficients $\left(C_{s}\right.$ and $\left.C_{c}\right)$ with the electrodes diameter ratios $\left(D_{1} / D_{2}\right)$, calculated at $\left(V_{1}=100 \mathrm{~V}\right.$ and $\mathrm{V}_{2}=3 \mathrm{kV}$ ), at the finite magnification condition.

\section{CONCLUSIONS}

A method is presented in this research to determine the relative values of the electrodes bore diameter for new design of immersion electrostatic lens combined from the planarapertured and the tubular electrodes. The first electrode facing the incident electron beam has a conical bore shape while the second electrode has a conventional cylindrical bore shape. It has been found that the best bore diameter ratio equals (0.66) and this corresponds to the values of $\left(\mathrm{D}_{1}=4 \mathrm{~mm}\right)$ and $\left(\mathrm{D}_{2}=6 \mathrm{~mm}\right)$, respectively.

\section{REFERENCES}

Al-Khashab, M. A.; Al-Abdullah, A. E. (2012). The confront electrodes faces curvature effect on the electron gun performance. J. Raf. Sci., 23(2), 138-147.

Al-Khashab, M. A.; Al-Shamma, M. T. (2009). The effect of multi-electrodes on the optical performance of the electrostatic immersion lens. Dirasat, Pure Science, 36(2), 171182.

Grivet, P. (1965). "Electron Optics". Part 1, Pergamon Press, London, Ch.4, pp. 85-119.

Hawkes, P. W. (1972). "Electron Optics and Electron Microscopy", Taylor and Francis Ltd., London, Ch.2, pp. 27-44.

Hawkes, P. W. (2004). Recent advances in electron optics and electron microscopy, Annales de la Fondation Louis de Broglie, 29(1), 837-855.

Hawkes, P. W.; Kasper, E. (1996). "Principles of Electron Optics". Part 2, ACADIMIC PRESS, Inc., Ch.35, pp. 629-686.

Heddle, D.W.O. (2000). "Electrostatic Lens Systems”. 2nd edn., IOP Press, London, Ch.5, pp. 80-103. 
Hinterberger, F. (2005). "The Physics of Particle Accelerators". Springer-Verlag, Berlin Heidelberg New York, Ch.'s (4 and 5).

Khursheed, N.; Karuppiah, N. (2002). A high-resolution mixed field immersion lens attachments for conventional scanning electron microscope. American Inst. Phys., 73(8), 2906-2909.

Lawson, J. D. (1988). "The Physics of Charged Particle Beams". Clarendon Press, Oxford, Ch.5, pp. 161-201.

Liebl, H. (2008). “Applied Charged Particle Optics”. Springer, Ch.'s (2-4), pp. 45-104.

Munro, E. (1975). "A Set of Computer Programs for Calculating the Properties of Electron Lenses", Cambridge University, Eng., Dept., Report CUED/B-ELECT/TR 45.

Septier, A. (1980). "Applied Charged Particle Optics". ACADEMIC PRESS, INC. 24/28 Oval Road, London NW1 7DX.

Sinno, I. ; Sanz-Velasco A.; Kang, S.; Jansen, H.; Olsson, E.; Enoksson, P.; Svensson, K. (2010). Fabrication of nanoscale electrostatic lenses. IOP Pup. J. Micromechanics and Microenginering (www.iopscience.iop.org /0960-317/20/9/095031).

Sise, O.; Ulu, M.; Dogan, M. (2005). Multi-element electrostatic lens systems for focusing and controlling of charged particles. Nucl. Instrum. Methods. A. 54, 114-131.

Syms, R. R. A.; Michelutti, L.; Ahmad, M. M. (2003). Two-dimension microfabricated electrostatic einzel lens. www.sciencedirect.com, Sensors and Actuators A107, 285295.

Szilagyi, M. ; Szep, J. (1988). Optimum design of electrostatic lens. J. Vac. Sci. Technol., B6, 953-957.

Zworykin, V. K.; Morton, G. A.; Ramberg, E. G.; Hillier, J.; Vance, A. W. (1945). "Electron Optics and The Electron Microscope". Wiley, New York. 